\title{
Evaluation of the visual prostate symptom score in a male population with great language diversity and limited education: A study from Namibia
}

\author{
C F Heyns, ${ }^{1}$ MB ChB, MMed (Urol) PhD, FCSSA (Urol); B A Steenkamp, ${ }^{1}$ BSc, MB ChB; J Chiswo, ${ }^{2}$ MB ChB; \\ G A Stellmacher, ${ }^{2} \mathrm{MB} \mathrm{ChB}, \mathrm{MMed}$ (Urol); H E A Förtsch, ${ }^{2} \mathrm{MB} \mathrm{ChB}, \mathrm{MMed}(\mathrm{Urol})$, FCSSA (Urol); \\ A van der Merwe, ${ }^{1} \mathrm{MB}$ ChB, $\mathrm{MMed}(\mathrm{Urol})$ FCUrol (SA) \\ ${ }^{1}$ Department of Urology, Faculty of Health Sciences, Stellenbosch University and Tygerberg Hospital, Tygerberg, Cape Town, South Africa \\ ${ }^{2}$ Department of Urology, Windhoek Central Hospital, Namibia
}

Corresponding author: C F Heyns (cfh2@sun.ac.za)

\begin{abstract}
Background. A visual prostate symptom score (VPSS) using pictograms was developed to assess the force of the urinary stream, urinary frequency, nocturia and quality of life (QoL).

Objective. To compare the VPSS with the international prostate symptom score (IPSS) and maximum (Qmax) and average (Qave) urinary flow rates in men from diverse language groups with limited schooling.

Methods. Men with lower urinary tract symptoms admitted to the urology ward at Windhoek Central Hospital, Namibia, were evaluated. Patients who were unable to complete the questionnaires alone were assisted by a doctor or nurse. Local ethics committee approval was obtained. Statistical analysis was performed using Student's $t$-test and Spearman's rank correlation test.

Results. One hundred men (mean age 56.3 years, range 20.1 - 95.4) were evaluated over a period of one year. All the men understood one or more of 15 languages, and 30 were illiterate; 32 had $<5$ years of schooling, 34 had 5 - 9 years and 34 had $>9$ years. The VPSS took significantly less time to complete than the IPSS. There were statistically significant correlations between the total VPSS and IPSS scores, between the four VPSS questions and the corresponding IPSS questions, and between Qmax and Qave and the VPSS total and VPSS questions on the force of the urinary stream and QoL.

Conclusion. The VPSS pictograms depicting the force of the urinary stream and QoL correlated significantly with Qmax and Qave, indicating that they can be used as single-item questions to rapidly assess bladder outflow obstruction in men with limited education.
\end{abstract}

S Afr Med J 2014;104(5):353-357. DOI:10.7196/SAMJ.7917



The international prostate symptom score (IPSS) (Fig. 1) is used widely to assess lower urinary tract symptoms (LUTS) in men before and after treatment. ${ }^{[1]}$ The IPSS is relatively complicated, especially for patients with low education levels, and elderly patients with visual impairment may find it difficult to read the small print. ${ }^{[2-4]}$

Illiteracy is a major problem with administration of the IPSS in developing countries. ${ }^{[5]}$ Translating the IPSS into various languages requires extensive validation studies and constant surveillance to ensure consistency. ${ }^{[6]}$

A drawback of the IPSS is that it does not evaluate all lower urinary tract symptoms, such as incontinence, pain or macroscopic haematuria. More comprehensive questionnaires have been developed, such as the Core LUTS Score with 10 questions, and the EpiLUTS tool evaluating 18 symptoms. ${ }^{[7,8]}$ While providing more information, these require a high level of patient education, are timeconsuming to administer and analyse, and may not be useful for clinical application.

Some authors have proposed using fewer questions that may be more useful in clinical practice. A previous study has indicated that an abbreviated form of the IPSS consisting of three or four questions only may be used to assess patients more rapidly. ${ }^{[3]}$ It has also been suggested that the IPSS quality of life (QoL) question alone is as useful as the more complicated Benign Prostatic Hypertrophy Impact Index (BPH-II) ${ }^{[9]}$
Others have proposed the use of single-item questionnaires, which have the advantages of speed and ease of administration and interpretation, but the disadvantage that a single question cannot quantify the variety of symptoms present, their intensity, duration and frequency, or the distress they cause. ${ }^{[1]} \mathrm{A}$ recent study indicated that patients' perceptions of the severity of and changes in their symptoms can be captured with single-item questions that are simple, valid and easily administered. ${ }^{[10]}$

We developed a visual prostate symptom score (VPSS) that uses pictograms to assess the force of the urinary stream, daytime urinary frequency, nocturia and QoL. ${ }^{[1-13]}$ At the time we were unaware that Peeling ${ }^{[14]}$ had described a pictogram representing the force of the urinary stream in 1989, and that in 2006 Ushijima et al. ${ }^{[15]}$ had described a visual analogue scale for the IPSS, consisting of facial pictograms with expressions ranging from a broad smile (delighted) to a tearful face (distressed).

\section{Objective}

To compare the IPSS and VPSS with urinary flow rate measurements in men with LUTS who were illiterate or had very limited schooling, and who spoke a diversity of languages.

\section{Methods}

Men with LUTS admitted to the urology ward at Windhoek Central Hospital, Namibia, were evaluated with the IPSS (Fig. 1) and the VPSS (Fig. 2). Maximum (Qmax) and average (Qave) urinary flow 
rates were measured using a Dantec Urodyn flowmeter. The original version of the VPSS ${ }^{[1,12]}$ was modified in a subsequent study. ${ }^{[13]}$ The pictogram of the force of the urinary stream (question 3 in the original version) was moved to become question $\mathrm{A}$, because the pictogram of urination made it easier for the patient to understand the pictograms of frequency and nocturia (questions 2 and 3 in the original, and questions $\mathrm{B}$ and C in the modified VPSS). ${ }^{[11-13]}$

The following demographic data were collected: the patient's age, his mother's language, his home language, which languages he was able to understand, speak and read or write, years of schooling, occupation and monthly income. The patient was requested to fill in the IPSS and VPSS, with assistance if necessary from a physician and/or a nurse able to speak the patient's home language. The time taken to fill in the IPSS and the VPSS was recorded using a stopwatch.

The following clinical data were collected: findings on digital rectal examination, urine dipstick analysis, Qmax and Qave, voided volume (VV), serum creatinine, serum prostate-specific antigen, findings on cystoscopy, treatment given and histological results. Patients were requested to return for follow-up at 3 and 6 months after treatment.

The study protocol was approved by the Ministry of Health and Social Services of Namibia. Statistical analysis was performed with Student's $t$-test (paired or unpaired, as appropriate) for parametric data, Spearman's rank test for correlations and Fisher's exact test for contingency tables, using GraphPad InStat software.

\section{Results}

During the period February 2012 - February 2013, a total of 100 new patients were evaluated; 39 returned for follow-up, with a total of 155 visits (some patients had more than one follow-up visit). The distance between the patient's home and the hospital was $<100 \mathrm{~km}$ in 44 cases, $100-500 \mathrm{~km}$ in 32, $500-1000 \mathrm{~km}$ in 22 and $>1000 \mathrm{~km}$ in

International Prostate
Symptom Score (I-PSS)1
Date_

Fig. 1. International prostate symptom score. ${ }^{[1]}$ two. Overall, 25 patients had never attended school. The number of years at school was $<5$ years in 32 cases, $5-9$ years in 34 and $>9$ years in 34. Overall, 30 patients were not able to read or write.

Table 1 shows the mother languages of the patients, and the languages they spoke at home and were able to understand, speak and read or write. The number of languages understood by the patients was one in $21 \%$ of cases, two in $35 \%$, three in $23 \%$, four in $16 \%$ and five in $5 \%$. Table 2 shows the number of languages understood by the patients in the five most common language groups.

On admission to hospital, 19 men had an indwelling suprapubic catheter and 14 an indwelling transurethral catheter. The mean duration of catheterisation was 3.7 months (range 0.1 - 41.3). For these men, the symptom scores for the month before catheterisation were obtained; uroflowmetry could not be undertaken. The final diagnosis was urethral stricture in $61 \mathrm{men}$, benign prostatic hyperplasia (BPH) in 32 , no abnormality on cystoscopy in five, prostate cancer in three, prostatitis in three, bladder stones in two and bladder neck stenosis in one (some patients had more than one diagnosis). The surgical treatment involved direct-vision internal urethrotomy in 60 cases, transurethral resection of the prostate in 17, open prostatectomy in six, bladder neck incision in one and urethroplasty in one.

Both the IPSS and VPSS were filled in without assistance by only 18 of patients at the first visit, 82 requiring assistance. At follow-up the IPSS and VPSS were filled in without assistance by $7 / 55(12.7 \%)$ and $8 / 55$ (14.5\%) of patients. For all visits, the mean time taken to complete the IPSS and VPSS was 278 seconds (range 80 - 690) and 124 seconds (30 - 556), respectively $(p<0.0001)$. Comparing the first with follow-up visits, the mean time taken to complete the IPSS was 306 seconds (80 $690)$ v. 227 seconds ( 80 - 572), and the mean time taken to complete the VPSS was 173 seconds $(30-556)$ v. 100 seconds $(30-270)(p<0.001)$ Table 3 compares the groups of men with schooling $<5 \mathrm{v}$. $>9$ years.



Fig. 2. Visual prostate symptom score consisting of pictograms to evaluate (A) force of the urinary stream, (B) daytime frequency, (C) nocturia, and (D) quality of life. 
Table 1. Languages of the study group $(N=100)$

\begin{tabular}{|c|c|c|c|c|c|}
\hline & $\begin{array}{l}\text { Mother's } \\
\text { language }^{*} \\
n\end{array}$ & $\begin{array}{l}\text { Home } \\
\text { language } \\
n\end{array}$ & $\begin{array}{l}\text { Able to } \\
\text { understand } \\
n\end{array}$ & $\begin{array}{l}\text { Able to } \\
\text { speak } \\
n\end{array}$ & $\begin{array}{l}\text { Able to } \\
\text { read/write } \\
n\end{array}$ \\
\hline Oshiwambo & 27 & 24 & 36 & 34 & 23 \\
\hline Otjiherero & 23 & 23 & 41 & 38 & 12 \\
\hline Afrikaans & 16 & 17 & 67 & 67 & 49 \\
\hline Damara & 12 & 11 & 20 & 19 & 8 \\
\hline Nama & 11 & 11 & 11 & 11 & 4 \\
\hline Himba & 3 & 3 & 3 & 3 & 0 \\
\hline Nyemba & 3 & 3 & 3 & 2 & 2 \\
\hline Portuguese & 2 & 2 & 3 & 3 & 2 \\
\hline Rukwangali & 2 & 1 & 4 & 2 & 1 \\
\hline Shilozi & 2 & 2 & 3 & 3 & 3 \\
\hline Dhemba & 1 & 1 & 1 & 1 & 0 \\
\hline English & 1 & 1 & 50 & 50 & 40 \\
\hline Mbukushu & 1 & 1 & 1 & 1 & 1 \\
\hline Sifwe & 1 & 1 & 1 & 1 & 1 \\
\hline German & 0 & 0 & 5 & 5 & 0 \\
\hline
\end{tabular}

Table 2. Number of languages understood by members of the study group with the most common mother languages

\begin{tabular}{llllll}
\hline & \multicolumn{5}{c}{ Languages understood $(N), \boldsymbol{n}(\%)$} \\
\cline { 2 - 6 } Mother's language & $\mathbf{1}$ & $\mathbf{2}$ & $\mathbf{3}$ & $\mathbf{4}$ & $\mathbf{5}$ \\
\hline Oshiwambo $(N=27)$ & $6(22.2)$ & $9(33.3)$ & $8(29.6)$ & $3(11.1)$ & $1(3.7)$ \\
Otjiherero $(N=23)$ & $11(47.8)$ & $6(26.1)$ & 0 & $5(21.7)$ & $1(4.3)$ \\
Afrikaans $(N=15)$ & 0 & $10(66.7)$ & $4(26.7)$ & $1(6.7)$ & 0 \\
Damara $(N=11)$ & 0 & 0 & $4(36.4)$ & $5(45.5)$ & $2(18.2)$ \\
Nama $(N=9)$ & 0 & $6(66.7)$ & $2(22.2)$ & $1(11.1)$ & 0
\end{tabular}

Table 4 shows the correlations between the various VPSS and IPSS questions, Qmax and Qave in the study group as a whole, and Qmax and Qave in patients with VV $>150 \mathrm{ml}$ and $<150 \mathrm{ml}$. Comparing the groups with $\mathrm{VV}>150 \mathrm{ml}$ and $<150 \mathrm{ml}$, there were significant correlations between the total VPSS and total IPSS (0.934 v. 0.741, respectively) and between the VPSS and IPSS questions related to the force of the stream (0.775 v. 0.541) and QoL (0.902 v. $0.692)$. In the group with $\mathrm{VV}>150 \mathrm{ml}$ there were significant correlations between Qmax and the IPSS and VPSS questions on the force of the urinary stream $(-0.365 \mathrm{v}$. -0.456$)$ and QoL (-0.284 v. -0.223). In the group with $\mathrm{VV}<150 \mathrm{ml}$ there were even stronger correlations between Qmax and the IPSS and VPSS questions on the force of the stream (-0.434 v. -0.425) and QoL (-0.501 v. -0.387). The same was true for correlations of Qave with the IPSS and VPSS questions about the force of the urinary stream and QoL.

\section{Discussion}

In a previous study of 96 men with LUTS referred to a urology outpatient clinic, Van der Walt et al. ${ }^{[1]}$ found that a greater proportion of patients with $<7 \mathrm{v}$. $>10$ years of schooling could complete the VPSS without assistance compared with the IPSS (68\% v. $13 \%$ and $92 \%$ v. $76 \%$, respectively). There were statistically significant correlations between the total VPSS and IPSS scores, and between the total VPSS, Qmax and Qave. In

Table 3. Comparison of patient groups with $<5 \mathrm{v}$. $>9$ years of schooling

\begin{tabular}{|c|c|c|c|c|}
\hline & $\begin{array}{l}\text { Whole group } \\
(N=100)\end{array}$ & $\begin{array}{l}\text { Schooling }<5 \text { years } \\
(N=32)\end{array}$ & $\begin{array}{l}\text { Schooling }>9 \text { years } \\
(N=34)\end{array}$ & $p$-value \\
\hline Age (years), mean (range) & $56.3(20.1-95.4)$ & $71(38.8-95.4)$ & $43.2(20.1-87.5)$ & $<0.0001$ \\
\hline Able to read and write, $\%$ & 70 & 22 & 100 & $<0.0001$ \\
\hline Income per month (Namibian \$), mean (range) & $3205(0-30000)$ & $1732(0-30000)$ & $5926(0-25000)$ & $<0.0001$ \\
\hline IPSS completed without assistance, $\%$ & 18 & 0 & 38 & $<0.0001$ \\
\hline VPSS completed without assistance, $\%$ & 18 & 0 & 44 & $<0.0001$ \\
\hline Time to complete IPSS (seconds), mean (range) & $278(80-690)$ & $324(148-690)$ & $294(80-630)$ & 0.366 \\
\hline Time to complete VPSS (seconds), mean (range) & $124(30-556)$ & $178(58-556)$ & $107(30-330)$ & 0.003 \\
\hline \multicolumn{5}{|l|}{ Correlations } \\
\hline \multirow[t]{2}{*}{ VPSS total v. IPSS total } & $r=0.863$ & $r=0.775$ & $r=0.673$ & \\
\hline & $p<0.0001$ & $p<0.0001$ & $p<0.0001$ & \\
\hline \multirow[t]{2}{*}{ VPSS QA (force of stream) v. IPSS Q5 (weak stream) } & $r=0.657$ & $r=0.589$ & $r=0.295$ & \\
\hline & $p<0.0001$ & $p=0.0007$ & $p=0.09$ & \\
\hline \multirow[t]{2}{*}{ VPSS QB (frequency) v. IPSS Q2 (frequency) } & $r=0.522$ & $r=0.379$ & $r=0.451$ & \\
\hline & $p<0.0001$ & $p=0.036$ & $p=0.008$ & \\
\hline \multirow[t]{2}{*}{ VPSS QC (nocturia) v. IPSS Q7 (nocturia) } & $r=0.898$ & $r=0.844$ & $r=0.851$ & \\
\hline & $p<0.0001$ & $p<0.0001$ & $p<0.0001$ & \\
\hline \multirow[t]{2}{*}{ VPSS QD (QoL) v. IPSS QoL } & $r=0.806$ & $r=0.635$ & $r=0.387$ & \\
\hline & $p<0.0001$ & $p=0.0001$ & $p=0.024$ & \\
\hline
\end{tabular}


Table 4. Correlations between the visual prostate symptom score, international prostate symptom score and maximum and average urinary flow rates

\begin{tabular}{|c|c|c|c|c|c|c|}
\hline \multirow[b]{2}{*}{ Spearman's rank correlation } & \multicolumn{2}{|c|}{ All follow-up visits $(N=155)$} & \multicolumn{2}{|c|}{$\mathrm{VV}>150 \mathrm{ml}(\mathrm{N}=57)$} & \multicolumn{2}{|c|}{$\mathrm{VV}<150 \mathrm{ml}(\mathrm{N}=44)$} \\
\hline & Coefficient $(r)$ & $p$-value & Coefficient $(r)$ & $p$-value & Coefficient $(r)$ & $p$-value \\
\hline \multicolumn{7}{|l|}{ VPSS v. IPSS } \\
\hline Total & 0.863 & $<0.0001$ & 0.934 & $<0.0001$ & 0.741 & $<0.0001$ \\
\hline $\begin{array}{l}\text { VPSS QA (force of stream) v. IPSS } \\
\text { Q5 (weak stream) }\end{array}$ & 0.657 & $<0.0001$ & 0.775 & $<0.0001$ & 0.541 & 0.0002 \\
\hline $\begin{array}{l}\text { VPSS QB (frequency) v. IPSS } \\
\text { Q2 (frequency) }\end{array}$ & 0.522 & $<0.0001$ & 0.525 & $<0.0001$ & 0.552 & 0.0001 \\
\hline $\begin{array}{l}\text { VPSS QC (nocturia) v. IPSS } \\
\text { Q7 (nocturia) }\end{array}$ & 0.896 & $<0.0001$ & 0.913 & $<0.0001$ & 0.907 & $<0.0001$ \\
\hline VPSS QD (QoL) v. IPSS QoL & 0.806 & $<0.001$ & 0.902 & $<0.0001$ & 0.692 & $<0.001$ \\
\hline \multicolumn{7}{|l|}{ Qmax v. IPSS } \\
\hline Total & -0.409 & $<0.0001$ & -0.284 & 0.038 & -0.371 & 0.022 \\
\hline Qmax v. IPSS Q2 (frequency) & -0.159 & 0.121 & -0.007 & 0.962 & -0.275 & 0.095 \\
\hline Qmax v. IPSS Q5 (weak stream) & -0.458 & $<0.0001$ & -0.365 & 0.007 & -0.434 & 0.006 \\
\hline Qmax v. IPSS Q7 (nocturia) & -0.082 & 0.427 & 0.142 & 0.304 & -0.186 & 0.263 \\
\hline Qmax v. IPSS QoL & -0.489 & $<0.0001$ & -0.284 & 0.038 & -0.501 & 0.001 \\
\hline \multicolumn{7}{|l|}{ Qmax v. VPSS } \\
\hline Total & -0.340 & 0.0007 & -0.174 & 0.208 & -0.362 & 0.026 \\
\hline Qmax v. VPSS QA (force of stream) & -0.522 & $<0.0001$ & -0.456 & 0.0005 & -0.425 & 0.008 \\
\hline Qmax v. VPSS QB (frequency) & -0.109 & 0.109 & -0.005 & 0.973 & -0.246 & 0.136 \\
\hline Qmax v. VPSS QC (nocturia) & -0.072 & 0.488 & -0.152 & 0.272 & -0.125 & 0.455 \\
\hline Qmax v. VPSS QD (QoL) & -0.368 & 0.0002 & -0.223 & 0.105 & -0.350 & 0.031 \\
\hline \multicolumn{7}{|l|}{ Qave v. IPSS } \\
\hline Total & -0.479 & $<0.0001$ & -0.441 & 0.0006 & -0.337 & 0.025 \\
\hline Qave v. IPSS Q2 (frequency) & -0.227 & 0.020 & -0.095 & 0.481 & -0.307 & 0.043 \\
\hline Qave v. IPSS Q5 (weak stream) & -0.481 & $<0.0001$ & -0.507 & $<0.0001$ & -0.289 & 0.057 \\
\hline Qave v. IPSS Q7 (nocturia) & -0.194 & 0.047 & 0.016 & 0.097 & -0.287 & 0.059 \\
\hline Qave v. IPSS QoL & -0.549 & $<0.0001$ & -0.437 & 0.0007 & -0.447 & 0.002 \\
\hline \multicolumn{7}{|l|}{ Qave v. VPSS } \\
\hline Total & -0.425 & $<0.0001$ & -0.334 & 0.011 & -0.371 & 0.013 \\
\hline Qave v. VPSS QA (force of stream) & -0.522 & $<0.000$ & -0.572 & $<0.0001$ & -0.413 & 0.005 \\
\hline Qave v. VPSS QB (frequency) & -0.165 & 0.109 & -0.077 & 0.570 & -0.222 & 0.147 \\
\hline Qave v. VPSS QC (nocturia) & -0.072 & 0.488 & 0.022 & 0.869 & -0.193 & 0.209 \\
\hline Qave v. VPSS QD (QoL) & -0.440 & $<0.0001$ & -0.379 & 0.004 & -0.333 & 0.027 \\
\hline
\end{tabular}

a further analysis of the uroflowmetry data, Heyns et al. ${ }^{[12]}$ found that the VPSS question on the subject's assessment of his urinary stream showed a significant negative correlation with Qmax $(r=-0.37$, $p=0.002)$ and Qave $(r=-0.31, p=0.011)$, whereas the IPSS question on the subject's urinary stream did not correlate significantly with Qmax or Qave. In a study of 100 men followed up after a diagnosis of urethral stricture, Wessels and Heyns ${ }^{[13]}$ found that the VPSS correlated significantly with the IPSS, Qmax and urethral diameter and took significantly less time to complete than the IPSS.

In the current study, the mean patient age (56.3 years) was considerably lower than in other studies of men with LUTS (64 70 years). ${ }^{[5,9,11]}$ This is explained by the fact that the underlying pathology was urethral stricture in $61 \%$, with BPH in only $32 \%$ of the study cohort.

The majority of the patients (66\%) had $<10$ years of schooling, $25 \%$ had never attended school and $30 \%$ were illiterate. The patients with $<5$ years of schooling were significantly older than those with $>9$ years of schooling (mean age 71 v. 43.2 years) (Table 3), indicating that the older men grew up in a time when access to school education was less readily available.

The study patients all spoke one or more of 15 languages, so it is not surprising that $82 \%$ overall, and $100 \%$ in the group with $<5$ years of schooling, required assistance to complete the IPSS and VPSS. The time taken to complete the VPSS was significantly less than that for the IPSS for the group as a whole (124 v. 278 seconds) and also in the groups with $<5$ years of schooling (178 v. 324 seconds) v. $>9$ years of schooling (107 v. 294 seconds), confirming that the VPSS takes less time to complete than the IPSS, especially in men with limited education. ${ }^{[1]]}$ The mean time to complete both the IPSS and VPSS was shorter at follow-up (173 and 100 seconds) than at the first visit (306 and 227 seconds), indicating that patients learn how to answer the questions more quickly. 
The group with lower schooling $(<5$ years v. $>9$ years $)$ showed stronger correlations between the total VPSS and total IPSS, between VPSS question A and IPSS question 5 (force of the urinary stream), and between the VPSS and IPSS QoL questions (Table 3). This indicates that the correlations between the VPSS and IPSS scores may be even better in men with very limited schooling than in those with a higher level of schooling.

Although it is generally accepted that Qmax and Qave are only reliable if the VV is $>150 \mathrm{ml}$, in a study of 1271 men Reynard et al. ${ }^{[16]}$ found that low-volume uroflowmetry can provide useful diagnostic information and the data from such voids should therefore not be discarded. In their study, those voiding $<150 \mathrm{ml}$ had a $72 \%$ likelihood of bladder outlet obstruction, while in those voiding $>150 \mathrm{ml}$ the likelihood was $56 \%{ }^{[16]}$

Comparing the groups with VV $>150 \mathrm{ml} v$. $<150 \mathrm{ml}$ in the current study, there were significant correlations between the total VPSS and total IPSS and between the VPSS and IPSS questions related to the force of the stream and QoL (Table 4). In the group with VV $>150$ $\mathrm{ml}$ there were significant correlations between Qmax and the IPSS and VPSS questions on the force of the urinary stream and QoL. In the group with $\mathrm{VV}<150 \mathrm{ml}$ there were even stronger correlations between Qmax and the IPSS and VPSS questions on the force of the stream and QoL. The same was true for correlations of Qave with the IPSS and VPSS questions about the force of the urinary stream and QoL (Table 4).

\section{Conclusion}

The VPSS takes significantly less time to complete than the IPSS, especially in men with limited schooling. The VPSS correlates significantly with the IPSS with regard to total score, the questions about the force of the urinary stream, and overall QoL. Since the VPSS pictograms correlate significantly with the corresponding IPSS questions and Qmax and Qave, they can be used as single-item questions to rapidly assess the degree of bladder outflow obstruction in men who are illiterate or have limited education.
Source of funding. South African Urological Association.

\section{References}

1. Griffith JW. Self-report measurement of lower urinary tract symptoms: A commentary on the literature since 2011. Curr Urol Rep 2012;13(6):420-426. [http://dx.doi.org/10.1007/s11934-012-0286-5]

2. Cam K. BPH: How useful is a visual prostate symptom score for patients? Nat Rev Urol $2011 ; 8(10): 536-$ 537. [http://dx.doi.org/10.1038/nrurol.2011.137]

3. Cam K, Senel F, Akman Y, Erol A. The efficacy of an abbreviated model of the International Prostate . Cam K, Senel F, Akman Y, Erol A. The efficacy of an abbreviated model of the International Prostate
Symptom Score in evaluating benign prostatic hyperplasia. BJU Int 2003;91(3):186-189. [http://dx.doi. org/10.1046/j.1464-410X.2003.04055.x

4. Oztürk Mí, Koca O, Keleș MO, Güneș M, Kaya C, Karaman Mî. International prostate symptom score: Really appreciated by all patients or not? Urol J 2011;8(3):227-230.

5. Ogwuche EI, Dakum NK, Amu CO, Dung ED, Udeh E, Ramyil VM. Problems with administration of international prostate symptom score in a developing community. Ann Afr Med 2013;12(3):171-173. [http://dx.doi.org/10.4103/1596-3519.117628]

6. Kim JH, Doo SW, Yang WJ, Song YS. Homogeneity among the Korean international prostate symptom score questionnaires used in real practice. Korean J Urol 2013;54(4):249-251. [http://dx.doi. org/10.4111/kju.2013.54.4.249]

7. Fujimura T, Kume $\mathrm{H}$, Nishimatsu $\mathrm{H}$, et al. Assessment of lower urinary tract symptoms in men by international prostate symptom score and core lower urinary tract symptom score. BJU Int 2012;109(10):1512-1516. [http://dx.doi.org/10.1111/j.1464-410X.2011.10445.x]

8. Coyne KS, Barsdorf AI, Thompson C, et al. Moving towards a comprehensive assessment of lower 8. Coyne KS, Barsdorf AI, Thompson C, et al. Moving towards a comprehensive assessment of lower
urinary tract symptoms (LUTS). Neurourol Urodyn 2012;31(4):448-454. [http://dx.doi.org/10.1002/ urinary tract

9. O'Leary MP, Wei JT, Roehrborn CG, Miner M; BPH Registry and Patient Survey Steering Committee. 9. O'Leary MP, Wei JT, Roehrborn CG, Miner M; BPH Registry and Patient Survey Steering Committee.
Correlation of the International Prostate Symptom Score bother question with the Benign Prostatic Correlation of the International Prostate Symptom Score bother question with the Benign Prostatic
Hyperplasia Impact Index in a clinical practice setting. BJU Int 2008;101(12):1531-1535. [http:// dx.doi.org/10.1111/j.1464-410X.2008.07574.x

10. Viktrup L, Hayes RP, Wang P, Shen W. Construct validation of patient global impression of severity (PGI-S) and improvement (PGI-I) questionnaires in the treatment of men with lower urinary tract symptoms secondary to benign prostatic hyperplasia. BMC Urol 2012;12(1):30. [http://dx.doi. org/10.1186/1471-2490-12-30]

11. Van der Walt CL, Heyns CF, Groeneveld AE, Edlin RS, van Vuuren SP. Prospective comparison of a new visual prostate symptom score versus the international prostate symptom score in men with lower urinary tract symptoms. Urology 2011;78(1):17-20. [http://dx.doi.org/10.1016/j. urology.2011.01.065]

12. Heyns CF, Van der Walt CL, Groeneveld AE. Correlation between a new visual prostate symptom score (VPSS) and uroflowmetry parameters in men with lower urinary tract symptoms. S Afr Med J

13. Wessels SG, Heyns CF. Prospective evaluation of a new visual prostate symptom score, the international prostate symptom score, and uroflowmetry in men with urethral stricture disease. Urology 2014;83(1):220-224. [http://dx.doi.org/10.1016/j.urology.2013.08.058]

14. Peeling WB. Diagnostic assessment of benign prostatic hyperplasia. Prostate Suppl 1989;2:51-68.

15. Ushijima S, Ukimura O, Okihara K, Mizutani Y, Kawauchi A, Miki T. Visual analog scale questionnaire to assess quality of life specific to each symptom of the International Prostate Symptom Score. J Urol 2006;176(2):665-671. [http://dx.doi.org/10.1016/j.juro.2006.03.031]

16. Reynard JM, Yang Q, Donovan JL, et al. The ICS-'BPH' Study: Uroflowmetry, lower urinary tract symptoms and bladder outlet obstruction. Br J Urol 1998;82(5):619-623. [http://dx.doi.org/10.1046/ j.1464-410X.1998.00813.x]

Accepted 18 February 2014. 